\title{
Pathology of Spontaneous Dissection of Intracranial Arteries
}

\author{
John H.N. Deck
}

\begin{abstract}
Spontaneous dissection of a major subarachnoid artery is an uncommon cause of stroke in young and apparently healthy individuals. Such dissection does not correlate well with systemic conditions such as emboli, thrombotic or hemorrhagic tendencies or hypertension, nor with disease of blood vessels such as atherosclerosis, fibromuscular dysplasia, cystic medial necrosis or Moya-Moya disease. Unusual exertion has been implicated as a factor in some cases. Gap defects were found in the internal elastic lamina near the site of dissection in three of four cases of spontaneous dissection reported here. It is suggested that such defects, because of their unusual size or number, may be responsible for initiating dissection in susceptible individuals. A detailed study of the major cerebral arteries in cases of dissection and control cases to document the size and frequency of such defects could shed light on the pathogenesis of spontaneous dissection. The subsequent course of events tends to differ in the internal carotid and vertebro-basilar systems. In most cases, the dissection in the internal carotid system is sub-intimal leading to thrombosis and cerebral infarction, while in the vertebrobasilar system dissection lies between the media and adventitia leading to subarachnoid hemorrhage. It is not known what structural differences of the two arterial systems may underlie this difference in the pattern of arterial dissection.
\end{abstract}

RÉSUMÉ: Pathologie de la dissection spontanée au niveau des artères intracrâniennes La dissection spontanée d'une artère sous-arachnoïdienne importante est une cause rare d'accident cérébro-vasculaire chez les individus jeunes et apparemment en bonne santé. Il n'existe pas de corrélation claire entre cette dissection et des affections systémiques telles l'embolie, la tendance à la thrombose ou à l'hémorragie, l'hypertension, ni avec des maladies des vaisseaux sanguins telles l'athérosclérose, la dysplasie fibromusculaire, la nécrose kystique de la média ou la maladie de Moya-Moya. Dans certains cas, un des facteurs impliqués était un effort inusité. Chez trois des quatre cas que nous rapportons, nous avons décelé des défauts lacunaires dans la lame élastique interne près du site de dissection. Nous suggérons que ces défauts, à cause de leur taille ou de leur nombre, peuvent être le point de départ du processus de dissection chez les individus qui y sont susceptibles. Une étude détaillée des artères principales du cerveau chez les cas de dissection et chez des contrôles, dans le but d'obtenir des informations sur la taille et la fréquence de ces défauts pourrait nous éclairer sur la pathogénèse de la dissection spontanée. Le déroulement ultérieur des événements se présente un peu différemment dans le système de la carotide interne et le système vertébro-basilaire. Dans la plupart des cas, la dissection dans le système de la carotide interne est sous-intimale entraînant une thrombose et un infarctus cérébral, tandis que dans le système vertébro-basilaire, la dissection se fait entre la média et l'adventice, entraînant une hémorragie sous-arachnoïdienne. Les différences structurales entre les deux systèmes artériels sous-jacentes à cette différence dans le pattern de dissection artérielle, ne sont pas connues.

Can. J. Neurol. Sci. 1987; 14:88-91

Stroke in a young and apparently healthy person presents a major problem in diagnosis and management. Strokes in the young are most often hemorrhagic, due to rupture of a berry aneurysm or a vascular malformation and, in such cases, CT scan and angiography will usually establish the diagnosis. Ischemic stroke may be the result of embolism related to cardiac disease or thrombosis related to contraceptive therapy, both recognized risk factors for stroke. Among the less common causes of both hemorrhagic and ischemic stroke, is spontaneous dissection of a major subarachnoid artery. No risk factors have as yet been identified and the underlying vascular defect in such cases is poorly understood as are the factors which may precipitate the catastrophic event.

Cases of spontaneous dissection can be divided into those involving the terminal internal carotid artery (ICA), the middle cerebral artery (MCA), the basilar artery (BA) and vertebral artery (VA). The consequences of dissection of arteries in the anterior circulation are likely to be different from those in the posterior circulation as the following cases illustrate.

\section{Case I}

A thirty-eight year old man was found collapsed and unresponsive in a bathhouse. There was no evidence of recent trauma. At hospital, he was febrile and right hemiplegic and CT scan showed left cerebral edema with mass effect. Differential diagnosis included cerebral infarction from unknown cause, Herpes simplex encephalitis and infection related to suspected AIDS. Left cerebral biopsy showed recent infarction. He died four days later.

Autopsy showed death to be the result of left cerebral mass effect with ensuing brainstem compression and secondary brainstem hemorrhages. Brain swelling was the result of recent infarction of the entire territory of the left MCA (Figure 1). The artery, from its origin and

From the Division of Neuropathology. Department of Pathology. University of Toronto and Toronto General Hospital

Reprint requests to: John H.N. Deck. Department of Pathology. Toronto General Hospital, 200 Elizabeth Street, Toronto, Ontario, Canada M5G 2C4 


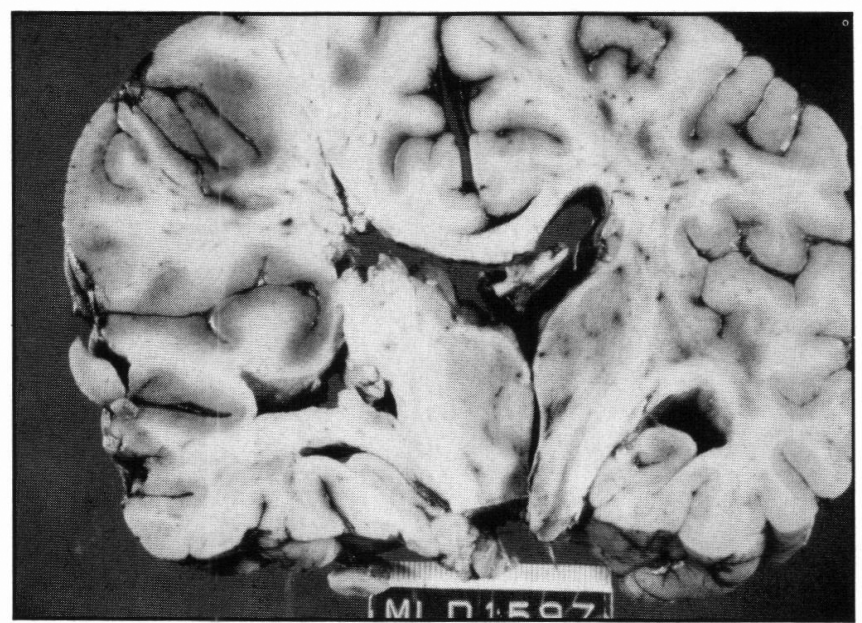

Figure I - Coronal section of brain (Case I) showing swelling of left cerebral hemisphere resulting from infarction of the left MCA territory three days before.

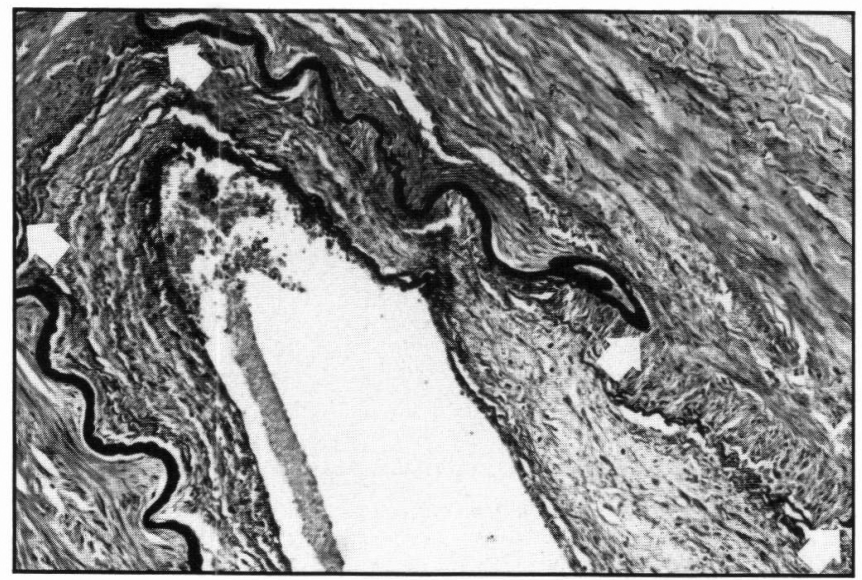

Figure 2 - Gap defects of the internal elastic lamina (between arrows) with mild fibrous thickening of intima in undissected proximal segment of $M C A$ (Case 1). Verhoff elastic stain Obj xl0.

including most branches within the Sylvian fissure, showed dissection between the intima and media with platelet-rich thrombus filling the false lumen so formed and compressing the true lumen to a crescentic slit. The most proximal segment of the MCA showed dissection of almost the entire circumference of intima, its absence from this segment indicating that the dissected intima had been swept distally by the flow of blood. Although media was never seen to be dissected with the intima. media external to the false lumen was reduced or absent in a few foci. The undissected internal elastic lamina showed small gap defects at several sites which were associated with somewhat thinned media and the formation of some intimal fibrous plaque (Figure 2).

Case 2

A twenty-two year old obese, normotensive woman collapsed on a subway platform without sustaining apparent injury in the fall. She was initially conscious but confused. At hospital, she was febrile and had no localizing neurological signs. a drug screen was negative. A psychiatric disorder was at first suspected but by the next morning right hemiparesis was noted and CT scan showed questionable enlargement of the left cerebral hemisphere. A white blood count was elevated prompting lumbar puncture which produced normal cerebrospinal fluid (CSF) at normal pressure. Within a minute, she suffered a cardiorespiratory arrest and although cardiac function was restored, she remained brain dead until the withdrawal of support twenty-four hours later.

Autopsy showed death to be the result of massive pulmonary thromboembolism. The left cerebral hemisphere was swollen as a result of infarction of the entire left MCA territory. The MCA, from its origin along all its branches out to the insula, was distended with blood.

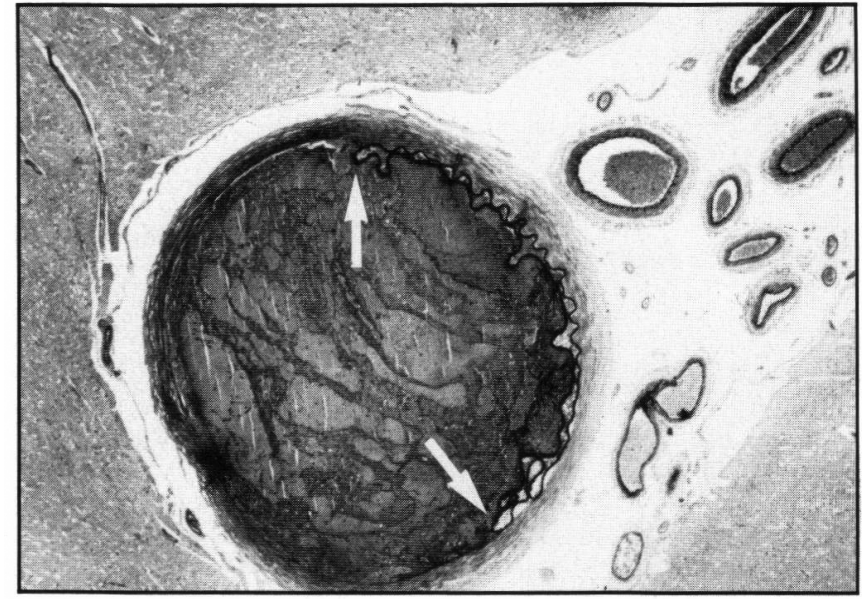

Figure 3-Branch of MCA showing dissection of intima of over half of the vessel circumference (arrows) and a laminated thrombus filling the false lumen so formed and compression of the true lumen to a crescentic slit. (Case 2). Verhoff elastic stain - Obj. x2.5.

and microscopic examination showed dissection of the arterial wall between intima and media; the false lumen so formed was filled with platelet-rich laminated thrombus which compressed the true lumen to a crescentic slit (Figure 3). Media was never seen to be dissected with the intima; however only adventitia separated the false lumen from the subarachnoid space at some foci, suggesting that stretching of the weakened vessel subsequent to dissection had reșulted in secondary tearing of the media. Both the dissected and undissected intima appeared normal. Virtually no atherosclerosis was present and no gap defects of the internal elastic lamina could be identified.

\section{Case 3}

A fifty-eight year old woman, with a long history of hypertension. suffered the abrupt onset of severe headache followed by stupor. At hospital. she was found to have neck stiffness and grossly bloody CSF. CT scan showed subarachnoid hemorrhage with some blood in the fourth ventricle. Cerebral angiography showed a somewhat bulbous right VA, suggesting an aneurysm and evidence of spasm elsewhere. Two weeks later. following a seizure and a sudden loss of consciousness. a CT scan showed evidence of rebleeding with blood in the ventricles and moderate hydrocephalus. She died one month after the onset of her illness.

At autopsy. there was leptomeningeal hemosiderosis and fresh subarachnoid hemorrhage, chiefly in the posterior fossa. Some recent infarction of the right frontal and temporal lobes was attributed to spasm. The right VA was the site of a fusiform aneurysm (Figure 4). the anterior wall of which was largely composed of organizing and fresh thrombus in which no remaining components of the vessel wall could be recognized (Figure 5). The posterior wall of the aneurysm was the site of a gap defect of the internal elastic lamina and a dissection. the plane of which lay within the media or between the media and adventitia and merged with the thrombus of the anterior wall of the aneurysm (Figure 6). No atheroma was present in the dissected arterial segment or elsewhere.

\section{Case 4}

A thirty-four year old normotensive man suffered the abrupt onset of headache followed by collapse and coma. At hospital, his neck wats stiff. he was afebrile and lumbar puncture produced grossly bloody CSF. Three-vessel angiography failed to reveal a source of subarachnoid bleeding. He remained semi-comatose until his death three weeks later from pneumonia.

Autopsy revealed an aneurysm of the right vertebral artery, the anterior wall of which was composed of thrombus showing early organization. The adjacent arterial wall showed rupture of the internal elastic lamina and media, and external to this. a plane of dissection within the adventitia (Figure 7). Communication of this dissection with the patent lumen of the artery could not be demonstrated in the longitudinal sections of the vessel wall. 


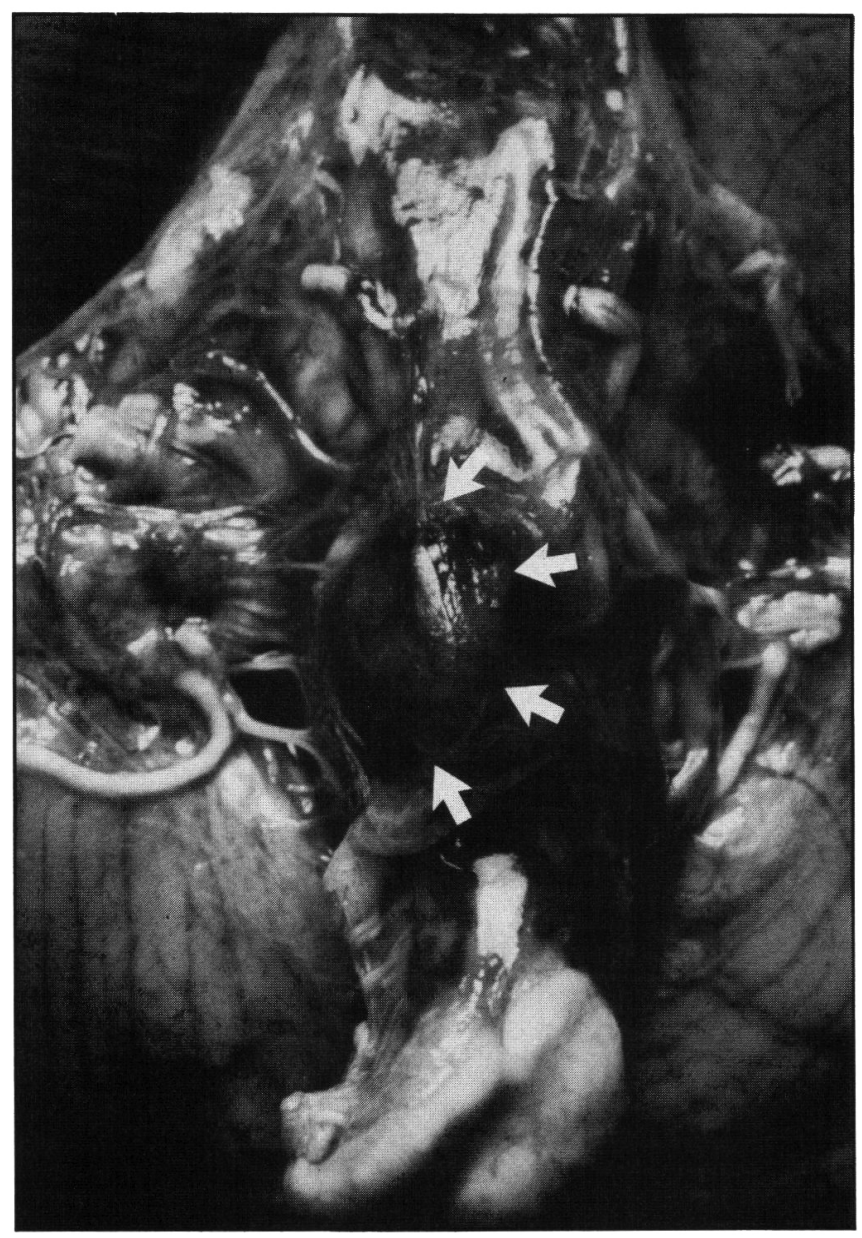

Figure 4-Cerebellumand brainstem from below (Case 3), showing fusiform aneurysm of right vertebral artery (arrows), largely obscured by fresh and older subarachnoid hemorrhage.

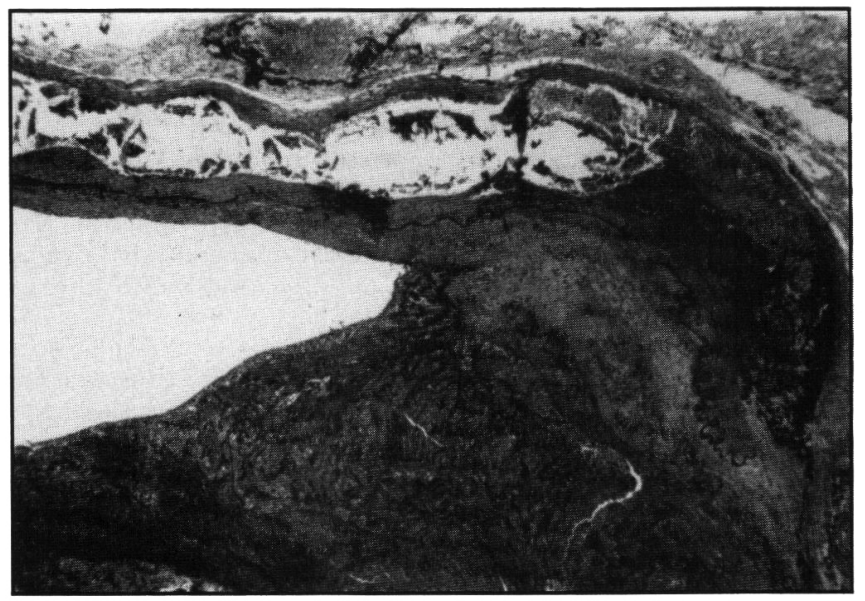

Figure 6-Dissection of the anterior aspect of the right vertebral artery between adventitia and media adjacent to organizing thrombus which replaces the vessel wall posteriorly. (Case 3). Mason trichrome-elastic. Obj. $\times 2.5$

\section{Discussion}

The tendency of spontaneous dissection of anterior cerebral circulation arteries to be subintimal and associated with thrombus and cerebral infarction, while that of posterior circulation

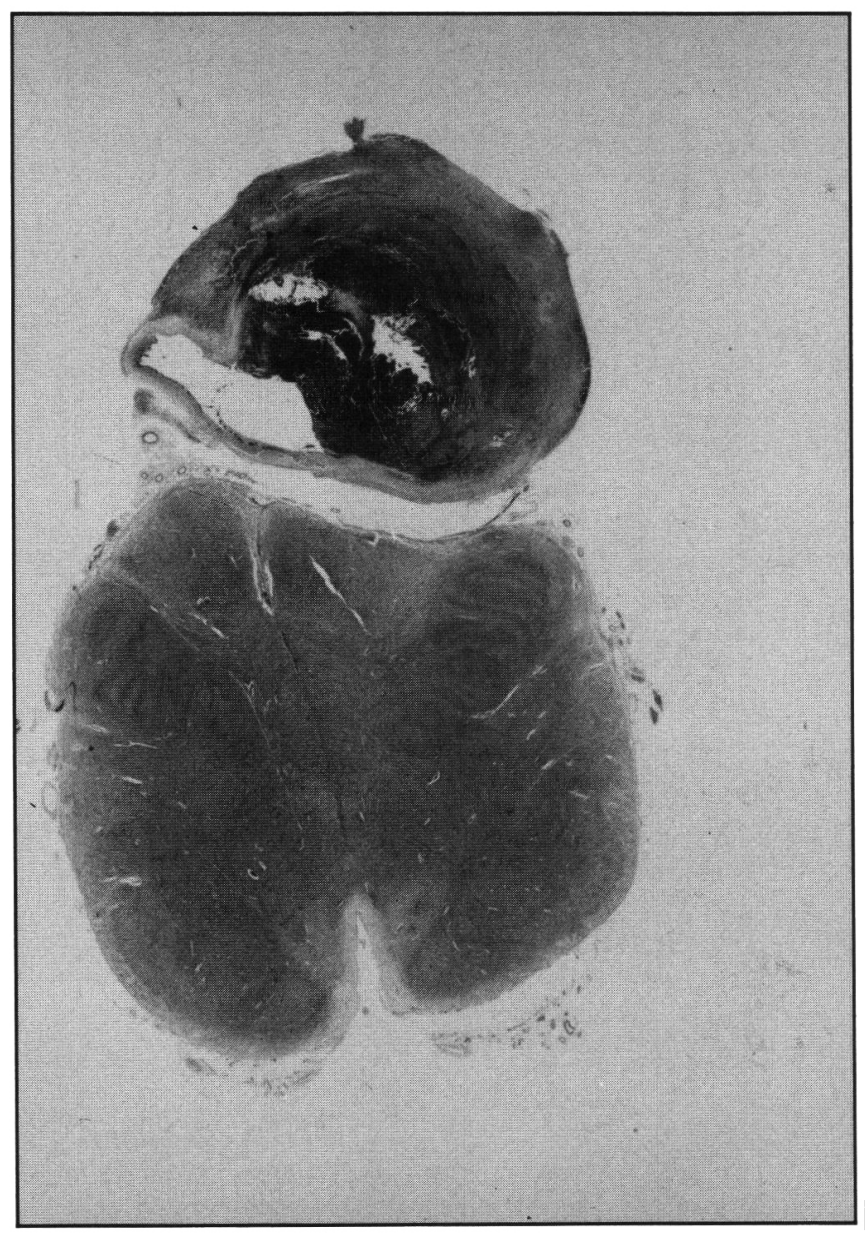

Figure 5 - Horizontal section of medulla somewhat compressed by aneurysmal enlargement of the right vertebral artery due to dissection; the anterior wall is composed only of organizing laminated thrombus. At this level, the dissection of the posterior wall is not seen. MSB-Elastic stain. (Case 3).

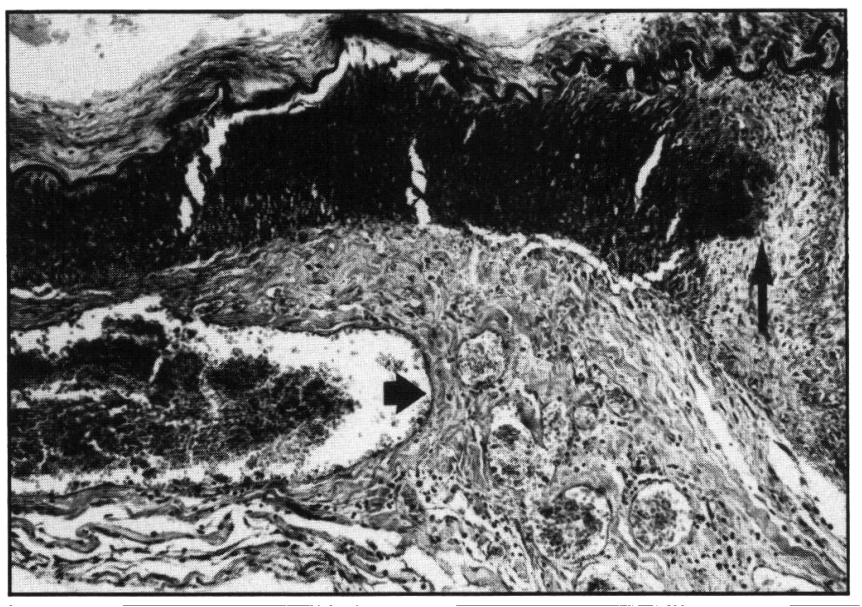

Figure 7 - Dissection of the right vertebral artery within the adventitia (shor arrows) adjacent to the site of rupture of the internal elastic lamina and media (long arrows) which bordered the base of an aneurysm. (Case 4). Verhoff elastic. Obj. xlo.

arteries is medial or subadventitial and associated with subarachnoid hemorrhage has been previously recognized, ${ }^{1.2}$ and is well illustrated by the four cases reported here.

A number of factors which may predispose to thrombotic or hemorrhagic stroke may be considered in the pathogenesis of 
dissection of intracranial arteries.

Embolic sources, thrombotic tendencies and hemorrhagic diatheses appear to be unlikely to cause the type of structural defect of the arterial wall seen in dissection and were not present in the four cases reported here.

Hypertension has been associated with only a minority of reported cases' and was present in only one of the four patients described in the present report. Thus, it seems unlikely to be an important factor in causing the dissection.

Trauma may be responsible for dissection of extracranial carotid arteries ${ }^{3}$ and, less commonly of intracranial arteries $;^{4}$ however, none of the cases reported here had a history of trauma and the apparently spontaneous nature of the ictus was a striking feature in each case. Subarachnoid hemorrhage has been reported following minor trauma to the head and neck in intoxicated individuals due to a tear through the full thickness of the vertebral artery, but not a dissection.

Unusual exertion has also been implicated in some recent reports 1.6 .7 of "spontaneous" dissection, but did not appear to be a factor in any of the four cases reported here.

Since factors such as emboli, thrombotic tendency, hemorrhagic diathesis, hypertension, exertion or trauma are not present in many cases of dissection, a strong suspicion is aroused that the vessel wall is the site of some underlying abnormality. If there were such a defect, then the factors listed above might still be important in determining the exact time at which a dissection occurred.

Predisposing vasculopathies which have been proposed include atherosclerosis,${ }^{8}$ fibromuscular dysplasia, ${ }^{9.10}$ and cystic medial necrosis. There was no clinical or pathological evidence of any of these in the present four cases. Association of dissection with Moya-Moya disease has also been reported, " but does not account for most reported cases of dissection.

Small gap defects of the internal elastic lamina were present in three of the four cases and have been reported before. ${ }^{12}$ Since dissection must begin with an intimal tear, it is tempting to consider intimal tears of importance in spontaneous dissection. The absence of documented gap defects in Case 2 might well represent the destruction of the area of defect by the process of dissection. The mechanical significance of such gaps is clearly related to their size, and were dissection to occur because of tearing of the intima at the edge of such a gap, the dissection would render histological evaluation of the site of tear virtually impossible. It is clear from their histologic appearance that gaps have been present long before the episode of dissection, possibly since birth. Reservations regarding their significance have been expressed ' since gaps are demonstrable in a high percentage of otherwise normal arteries. ${ }^{13}$

If gap defects are the important underlying vascular defect, then a detailed histological examination of all major intracranial arteries, not only those involved in the dissection, might be expected to disclose an increased number or size of such defects when compared with controls. Such a quantitative study has not yet been reported but could shed light on the question of pathogenesis of these rare but devastating lesions.

If gap defects of the internal elastic lamina are, in fact the significant underlying structural defect leading to spontaneous dissection, it is unlikely that they would be demonstrable by angiographic or other currently available methods of investiga- tion prior to the dissection event. Thus, identification of patients at risk is unlikely to be achieved.

It is postulated that a gap defect of the internal elastic lamina underlies spontaneous dissection in arteries of both the anterior and posterior circulation. If this is the case, what predisposes the anterior circulation to thrombosis and the posterior circulation to hemorrhage? In most cases, the plane of dissection is different at the two sites, the subintimal dissection correlating well with thrombosis and the subadventitial with hemorrhage.

It is not clear why the plane of dissection differs in the two arterial systems. Although differences in structure between subarachnoid and extracranial arteries of similar size are well documented, ${ }^{14}$ structural differences between the internal carotid and vertebrobasilar systems have not. It is suspected that differences in the structure of the media may exist making it more susceptible to tearing in the posterior than in the anterior circulation, but the nature of any such differences has not been investigated.

In summary, clinically unrecognizable defects consisting of gaps in the internal elastic lamina exist in some individuals and this may well be the defect underlying spontaneous dissection of major subarachnoid arteries. The plane of dissection of internal carotid and middle cerebral artery dissection is usually subintimal leading to thrombosis and infarction, while the plane of dissection of vertebral and basilar arteries is usually between the media and adventitia leading to subarachnoid hemorrhage.

\section{REFERENCES}

I. Farrel MA, Gilbert JJ, Kaufmann JCE. Fatal intracranial arterial dissection: clinical pathological correlation. J Neurol Neurosurg Psychiat 1985; 48: 111-121.

2. Friedman $A H$, Drake $C G$. Subarachnoid hemorrhage from intracranial dissecting aneurysm. J Neurosurg 1984: 60: 325-34.

3. Little JM, May J, Vanderfield GK and Lamond S. Traumatic thrombosis of the internal carotid artery. Lancet 1969:2:926.

4. Draz HM, Woodhall B. Traumatic dissecting aneurysm of left internal carotid, anterior cerebral and middle cerebral arteries. J Neuropath Exp Neurol 1947: 6: 286-91.

5. Deck JHN, Jagadha V. Fatal subarachnoid hemorrhage due to traumatic rupture of the vertebral artery. Arch Path Lab Med 1986; 110: 489-493.

6. Alexander CB, Burger PC, Goree JA. Dissecting aneurysms of the basilar artery in 2 patients. Stroke 1979; 10: 294-9.

7. Adelman LS, Doe FD, Sarnat HB. Bilateral dissecting aneurysms of the internal carotid arteries. Acta Neuropathol 1974:29:93-7.

8. Adams HP, Aschenbrener CA, Kassel NF, Ansbacher L, Cornell HS. Intracranial hemorrhage produced by spontaneous dissecting intracranial aneurysm. Arch Neurol 1982; 39: 773-6.

9. Pilz P, Hartjes HJ. Fibromuscular dysplasia and multiple dissecting aneurysms of intracranial arteries. Stroke 1976: 7: 393-8.

10. Pasquier B, N'Golet A, Pasquier D, Panh MC. Couderc P. Crouzet G. Hemodissection vertebro-basilaire: une observation anatomoclinique avec fibrodysplasie de l'artere vertebrale gauche. Sem Hop Paris 1979: 54:487-8.

11. Yamashita M, Tanaka K. Matsuo T. Yokoyama K. Fujii T. Sakamoto H. Cerebral dissecting aneurysms in patients with moyamoya disease. Report of two cases. J Neurosurg 1983; 58: 120-5.

12. Wolman L. Cerebral dissecting aneurysms. Brain 1959; 82: 276-91.

13. Campbell GJ, Eng P. Roach MR. Fenestrations in the internal elastic lamina at bifurcations of human cerebral arteries. Stroke 1981; 12: 489-96.

14. Baker AB, lannone A. The large arteries of the circle of Willis. Neurology 1959; 9: 321-332. 